\title{
Percepções de Mulheres que Vivenciaram o Aborto sobre Autonomia do Corpo Feminino
}

\author{
Camila Simões Santos \\ Universidade Federal do Rio de Janeiro, RJ, Brasil.
}

\author{
Lia Marcia Cruz da Silveira \\ Universidade Federal do Rio de Janeiro, RJ, Brasil.
}

\begin{abstract}
Resumo: $\mathrm{O}$ aborto é um tema de difícil diálogo devido aos diferentes posicionamentos morais que suscita, e obter um depoimento fiel das mulheres acerca do tema é delicado, pois se trata de uma temática que vai muito além da simples pergunta "você já praticou aborto?". Nesse sentido, antes de tratar dos motivos que levam uma mulher a decidir fazer um aborto, torna-se importante acolher o que essa mulher entende por autonomia, ou seja, como essa mulher percebe sua liberdade no trato com o próprio corpo. Desse modo, este estudo objetivou analisar o discurso de mulheres que vivenciaram o aborto sobre a autonomia do corpo feminino. Participaram do estudo 15 mulheres de idades entre 18 e 67 anos, o instrumento de coleta de dados utilizado foi a entrevista semiestruturada e o método de análise foi a "análise de discurso francesa", que busca evidenciar os sentidos que os sujeitos dão à realidade. As mulheres reconhecem a autonomia sobre seus corpos como uma liberdade de escolha, porém, quando se trata do aborto, essa escolha precisa ser velada. Portanto, mesmo considerando as decisões sobre uma gravidez e o possível aborto como um direito seu, nos discursos, o aborto apareceu ligado a um juízo de valor negativo.
\end{abstract}

Palavras-chave: Aborto, Autonomia, Corpo Feminino, Saúde da Mulher, Direitos Sexuais e Reprodutivos.

\section{Perceptions related to the Autonomy of the Female Body by Women who had Abortions}

\begin{abstract}
Abortion is a difficult theme to be dialogued as it raises different moral positions; this difficulty is also related to obtaining faithful testimonies from women, as this is an issue that goes beyond the simple question "did you already practice abortion?" In this sense, before dealing with the reasons that women have to decide to practice an abortion, it is important to know what these women mean by autonomy, i.e. how women see freedom in dealing with their own body. In this way, this study aimed to analyze the discourses, on the autonomy of the female body, of women who experienced abortion. The study included 15 women aged between 18 and 67 years, the data collection instrument used was the semi-structured interview and the method of analysis was the analysis of discourse that seeks to highlight the meanings that subjects give to reality. The main results demonstrated that women perceive the autonomy on their bodies as freedom, as "doing what you want" without having to justify. Women recognize the autonomy on their bodies as freedom of choice; however, when it comes to abortion this choice must be veiled. Therefore, even considering the decisions about pregnancy and about a possible abortion as rights, abortion in women discourses appeared connected to a negative value judgment.
\end{abstract}

Keywords: Abortion, Autonomy, Female Body, Women's Health, Sexual and Reproductive Rights. 


\title{
Percepciones sobre Autonomía del Cuerpo Femenino de Mujeres que Experimentaron Aborto
}

\begin{abstract}
Resumen: El aborto es un tema de difícil diálogo frente a las diferentes posiciones que morales que suscita y obtener un fiel testimonio de las mujeres sobre el tema es delicado, porque se trata de un problema que va más allá de la simple pregunta “Usted ya se practicó un aborto?” En ese sentido, antes de abordar las razones por las que una mujer decide abortar es importante abordar lo que esta mujer entiende por autonomía, es decir, cómo esta mujer percibe su libertad en las relaciones con el propio cuerpo. De esa manera, el presente estudio pretende analizar el discurso de las mujeres que han experimentado aborto, sobre la autonomía del cuerpo femenino. El estudio incluyó a 15 mujeres de edades comprendidas entre los 18 y los 67 años, el instrumento de recolección de datos utilizado fue la entrevista semiestructurada y el método de análisis fue el análisis del discurso, que pretende poner de relieve los significados que los sujetos dan a la realidad. Los principales resultados muestran que las mujeres perciben la autonomía sobre sus cuerpos como una libertad de "hacer lo que quieras" sin tener que justificarse. Las mujeres reconocen la autonomía sobre sus cuerpos como una libertad de elección, pero cuando se trata de aborto, esta elección debe ser velada. Por lo tanto, aun considerando las decisiones acerca de un embarazo y un posible aborto como un derecho, el aborto en sus discursos apareció conectado a un juicio de valor negativo.
\end{abstract}

Palabras clave: El aborto, La autonomía, El cuerpo de la mujer, La salud de la mujer, Los derechos sexuales y reproductivos.

\section{Introdução}

O aborto é um tema polêmico que suscita o embate de diversas áreas do conhecimento, envolvendo aspectos de cunho moral, religioso, social e legal. Pesquisar essa temática, na perspectiva de escuta às mulheres que vivenciaram tal experiência sob uma ótica diferente da abordada geralmente na mídia (forte carga emocional, moral e de defesa à vida do feto), não é simples, pois contar sobre uma gravidez interrompida desperta sentimentos de diferentes naturezas, além do receio de falar de um ato que no Brasil é considerado ilegal. No Brasil, o aborto só é permitido, segundo o artigo 128 do Código Penal brasileiro [Decreto-Lei No 2.848/1940 (Brasil, 1940)], em caso de risco de vida da gestante e de gravidez resultante de estupro. No entanto, recentemente, em 2012, a justiça brasileira julgou procedente a interrupção da gestação em casos de anencefalia sem qualquer autorização judicial para a realização do procedimento (Brasil, 2012).

Em relatório publicado pelo Ministério da Saúde (Brasil, 2009), intitulado Pesquisa Nacional de Aborto (PNA), realizou-se a sistematização das publicações dos últimos 20 anos sobre o tema aborto no Brasil. O objetivo de tal relatório foi organizar o conhecimento disperso e fortalecer o debate político sobre a temática. Entre os dados apresentados na pesquisa (Brasil, 2009), cabe destacar que, ao final de sua vida reprodutiva, mais de um quinto das mulheres no Brasil urbano praticou aborto. Sendo esse realizado de forma clandestina, muitas mulheres têm seus direitos violados e, por vezes, acabam perdendo a vida em procedimentos mal realizados e inseguros.

Nessa perspectiva, a problemática do aborto precisa ser enfrentada como uma questão de saúde pública e ligada aos direitos humanos, com repercussões abrangentes na vida da mulher e também de sua família. Pensar o aborto somente pela ótica do certo ou errado minimiza a reflexão sobre as consequências de tal prática, especialmente na vida das mulheres pobres sem acesso a recursos básicos de saúde como a contracepção.

Segundo Cook, Dickens e Fathalla (2004), condições sociais, econômicas, culturais, legais, entre outras, são barreiras que dificultam o avanço na melhoria da saúde das mulheres. Muitas vezes, aspectos sociais (analfabetismo, baixa educação, pouca oportunidade profissional etc.) empurram as mulheres jovens para o casamento e a maternidade precoces, e muitas não têm meios econômicos para o acesso à contracepção. A vulnerabilidade a abusos sexuais, dentro e fora do casamento, aumenta a inci- 
dência de gravidez indesejada e de abortos inseguros. Além disso, costumes sociais, religiosos e econômicos muitas vezes são usados, com respaldo legal, para discriminar as mulheres. Dessa forma, a atual legislação brasileira torna-se restritiva e anacrônica, não dando conta das reais necessidades das mulheres.

Apesar da abundância de estudos sobre o tema, percebemos que grande parte desses se mantêm articulados às questões relacionadas às repercussões físicas para a saúde das mulheres, seus perfis e a razão de terem realizado o aborto, não havendo um desdobramento de tais questões (Aquino \& Menezes, 2009; Brasil, 2009). No entanto, o tema aborto não está ligado apenas ao aspecto biologicista, mas também a concepções subjetivas, comportamentos sociais e condições socioeconômicas. A partir das possibilidades de entrelaçamentos que tal tema proporciona, surgiu o interesse de estudar a percepção das mulheres acerca de dois conceitos que estão diretamente ligados ao aborto: o corpo feminino e a autonomia.

Diante desses questionamentos, foi importante não restringir-se à pergunta "você já praticou aborto?", sem desconsiderar, é claro, os motivos da decisão de interromper a gestação, os determinantes que atravessam tal decisão, os meios usados, quando ocorreu e o porquê. Nessa abordagem foi proposta a investigação quais correlações de forças estão envolvidas no entendimento sobre a autonomia, o corpo feminino, a prática do aborto e como isso se expressa na fala da mulher, entendendo-a como sujeito ativo na construção da sua história.

No que diz respeito a valores, Barroco (2009) aponta que, mesmo em um determinado grupo ou estrato social, apesar dos valores e normas socialmente determinados, estes não são homogêneos; há um espaço para certa mobilidade, para ações diferentes daquelas impostas por uma moral dominante. É nesse sentido que surge a importância de ouvir e compreender o que a mulher sente e fala sobre autonomia, corpo feminino e aborto, pois, em suas relações sociais, a mulher põe em movimento diversas orientações de valores, que assumem um caráter político ao legitimar ou não a moral vigente.

Assim, elenca-se como objeto de estudo o discurso de mulheres que vivenciaram o aborto sobre a autonomia do corpo feminino, com o objetivo de identificar o entendimento das mesmas acerca da autonomia sobre seus corpos e analisar a articulação desse entendimento com a experiência de aborto.
Este estudo mostra-se relevante diante do cenário político e de saúde pública do país. Segundo relatório da Organização Mundial de Saúde (OMS), publicado em 2014, a mortalidade materna caiu menos no Brasil se comparada à média mundial. Entre 1990 e 2013, a queda no Brasil foi de $43 \%$, enquanto a média mundial foi de $45 \%$ e, entre as causas, o aborto aparece em sexto lugar, com 8\% dos casos (Brasil, 2014). Ainda segundo a Pesquisa Nacional de Aborto (Brasil, 2009), um dos desafios éticos para as futuras pesquisas em aborto é a necessária aproximação com os saberes femininos, visto que sabe-se pouco sobre o universo simbólico das mulheres que abortam.

Desse modo, esta pesquisa justifica-se pela magnitude das práticas abortivas em todo o país e pela necessidade da ampliação das discussões acerca desse assunto, visto que tal questão configura-se como um problema de saúde pública. Além disso, tal pesquisa visa explorar o universo simbólico feminino relacionando as temáticas aborto, autonomia e corpo feminino, legitimando a importância da aproximação aos saberes femininos, além de entender a necessidade de fornecer mais subsídios às discussões sobre os direitos sexuais e reprodutivos das mulheres.

Considerando, também, a Agenda Nacional de Prioridades de Pesquisa em Saúde do Ministério da Saúde, que tem como pressuposto "aumentar a indução seletiva para a produção de conhecimentos e bens materiais e processuais nas áreas prioritárias para o desenvolvimento das políticas sociais" (Brasil, 2008, p. 5), acredita-se que tal estudo é relevante para a Subagenda de Pesquisa em Saúde que trata da "Saúde da Mulher" em seu item "Magnitude, Dinâmica e Compreensão dos Problemas de Saúde da Mulher" do subitem "Abortamento".

Diante do exposto, torna-se importante referenciar o conceito de autonomia, sendo este um conceito transversal no que se refere ao corpo feminino e, por conseguinte, ao aborto. Para tanto, utiliza-se os autores Beauchamp e Childress (2011), estudiosos da área da Bioética, que empregam o conceito de autonomia para examinar a tomada de decisão, principalmente referente à saúde.

A palavra autonomia tem sentidos diversos entre as pessoas, tais como, autogovernar, direitos de liberdade, privacidade, escolha individual, entre outros, portanto, o conceito de autonomia não é algo fechado. Muitas ideias o constituem e, para tal conceito ganhar um sentido específico, é necessário inseri-lo no contexto 
de uma teoria. Assim, Beauchamp e Childress (2011) analisam a ação autônoma segundo uma teoria que considera três condições: agentes normais que agem intencionalmente; com entendimento; e sem influências controladoras que determinem sua ação.

A primeira condição da autonomia (a intencionalidade) não seria uma questão de grau: ou a pessoa tem a intenção ou não tem. Porém, as condições de entendimento e de ausências de influências controladoras podem ser satisfeitas de um modo mais ou menos completo. Deste modo, as ações podem ter graus de autonomia em função dos diferentes graus de satisfação dessas duas condições que estão em um amplo continuum, desde a presença total até a completa ausência (Beauchamp, \& Childress, 2011).

Mas como determinar se uma ação foi realmente autônoma? Segundo os autores citados (Beauchamp, \& Childress, 2011), seria necessário apenas um grau substancial de entendimento e de liberdade de alguma coerção e não um entendimento pleno ou uma completa ausência de influências. Porém, os critérios de definição de tal substancialidade devem estar contemplados em contextos particulares e não em teorias gerais que definam um grau de autonomia substancial.

Ou seja, podemos entender que dificilmente (ou seria quase impossível) nossas decisões serão tomadas de uma forma autônoma pura, pois estamos inseridos em um contexto social e cultural sob o qual somos influenciados o tempo todo e tais influências irão incidir de modo mais ou menos significativo em nosso entendimento sobre o mundo a nossa volta.

Dentro dessa perspectiva, de entender que a autonomia sobre um determinado aspecto da vida dependerá do grau substancial de liberdade que temos sobre esse aspecto e que tal grau sofrerá influências tanto das nossas próprias intenções quanto do contexto social que estamos inseridos (Beauchamp, \& Childress, 2011), podemos refletir como a construção simbólica do corpo feminino é atravessada por um contexto sócio-histórico e como essa construção desencadeia posicionamentos acerca da questão do aborto que, relacionados a um entendimento do que é ser mulher e do que é ser homem, leva, muitas vezes, à desigualdade de gênero.

As representações do corpo feminino foram construídas a partir de transformações históricas, econômicas, políticas e sociais que a sociedade sofreu e ainda sofre. Segundo Colling (2004), a partir de uma visão androcêntrica de identificação da humanidade, há uma hierarquização dos sexos na qual o masculino parece superior ao feminino. Para a autora, a história é uma construção, resultado de interpretações e representações que têm como pano de fundo relações de poder que, por vezes, beneficiam o sexo masculino. Assim, ao se admitir o caráter de construção da história também se admite a construção dos papéis feminino e masculino na sociedade.

Colling (2004) ainda cita que como o corpo é o primeiro lugar da inscrição. A sociedade encara a mulher a partir de seu corpo e de suas produções, fechando-as na reprodução e na afetividade, assim, o corpo seria o primeiro lugar de inscrição para a manifestação de controle sobre a mulher.

A medicalização do corpo feminino se desenvolve em meio à exaltação dos discursos à maternidade. Era dominante a ideia de uma natureza biológica que determinava a condição feminina. Desse modo, baseado nas condições biológicas do corpo feminino - menstruação, gestação, amamentação - é que decorre a ideia de "natureza feminina". Logo a mulher teria o instinto maternal, sendo a ela destinada a responsabilidade da maternidade e do cuidado com os filhos. Partindo-se disso, há uma divisão sexual do trabalho e uma divisão de gênero, por meio das quais a mulher cuida dos trabalhos domésticos e a ela são atribuídas as características de fragilidade e doçura, e o homem é destinado ao trabalho público, que necessita de força e virilidade.

Swain (2000) cita que os movimentos feministas colocaram em questão a "natureza humana" como sendo algo imutável e mostraram a multiplicidade do social e as possibilidades de atribuição de sentido às práticas, às pessoas, à cultura etc. Porém, ainda existe uma dicotomia que aprisiona o pensamento em um processo binário (natureza/cultura, real/imaginário, $\mathrm{bem} / \mathrm{mal}$ ) que faz com que se tenha uma apreensão e uma análise das relações sociais envoltas em um maniqueísmo de pares opostos ou complementares. Assim, os mecanismos de reflexão crítica por vezes ficam presos nessa dinâmica de homogeneização que esconde as múltiplas possibilidades do ser "eu" - as múltiplas possibilidades do que é ser mulher.

No atual cenário político brasileiro, o ativismo religioso também tem papel de destaque no debate sobre o aborto. Há um forte embate entre os movimentos feministas e LGBT e os ativistas religiosos em torno do sentido da vida e da percepção da sexualidade humana. Machado (2012) destaca que a tentativa de representantes na Câmara Legislativa de apre- 
sentar o aborto como uma questão de saúde pública e de propor a revisão da legislação com o intuito de garantir o acesso das mulheres aos serviços de saúde acirrou ainda mais a tensão entre os defensores de tal posicionamento e os religiosos tradicionalistas que defendem um discurso moral, familista e de controle da fertilidade feminina.

Em 2011, foram rejeitados pela Comissão de Seguridade Social e Família da Câmara dos Deputados quatro projetos de lei que tornava crime hediondo o aborto. Porém, os três últimos continuam tramitando vinculados ao primeiro e mais antigo [projeto de Lei $N^{\circ} 4.703 / 1998$ (Brasil, 1998)]. Mais recentemente, em outubro de 2015, a Comissão de Constituição e Justiça da Câmara dos Deputados aprovou o Projeto de Lei № 5.069/2013 (Brasil, 2013). Esse projeto modifica a lei de atendimento às vítimas de violência sexual, tornando obrigatório o exame de corpo de delito para comprovação da violência sexual antes do atendimento médico e retira do atendimento o fornecimento da pílula do dia seguinte; torna crime o anúncio de meios ou métodos abortivos; e penaliza quem induzir, instigar ou auxiliar em um aborto, com agravamento de pena para profissionais de saúde.

Tal projeto representa um retrocesso dos direitos humanos e reprodutivos das mulheres no Brasil, pois não impede que o aborto continue acontecendo e dificulta o acesso das mulheres à informação e à assistência médica. Além disso, poderá induzir que mais mulheres cometam o aborto inseguro, visto que condiciona o aborto legal ao exame de corpo de delito, desrespeitando, assim, a vontade da mulher de escolher denunciar a agressão sexual sofrida e levanta suspeita com relação à veracidade do que é relatado pela mulher vítima de violência sexual. Em outubro de 2015, ocorreram diversas manifestações pelo país convocada pelo movimento feminista contra tal projeto, refletindo uma reivindicação política pela não aprovação dessa lei (Rossi, 2015).

\section{Método}

Para o presente estudo, optou-se pela realização de uma pesquisa de caráter qualitativo, tendo como fonte primária de dados o discurso de mulheres atendidas no ambulatório de enfermagem ginecológica inserido na Unidade de Cuidados Básicos (UCB) do Instituto de Atenção à Saúde São Francisco de Assis (Hesfa).
O Hesfa, localizado no município do Rio de Janeiro, RJ, faz parte do Complexo Hospitalar da Universidade Federal do Rio de Janeiro (UFRJ). A UCB é a unidade assistencial do Hesfa responsável por assegurar os atendimentos ambulatoriais que envolvam ações de prevenção, promoção e recuperação da saúde em nível primário. Assim, pelo fato de o ambulatório ginecológico ser um local destinado a assistir a saúde da mulher e porque as mulheres ali atendidas estão em um momento de cuidado do seu corpo, foi escolhido esse cenário por ser propício a tratar dos temas elencados por esta pesquisa (autonomia, corpo feminino e aborto).

Considerando o objeto de estudo e os objetivos desta pesquisa, elegeu-se como técnica de coleta de dados a entrevista individual com um instrumento semiestruturado e, como fonte secundária de dados, utilizou-se os prontuários para obtenção de dados referentes exclusivamente à ocorrência ou não de uma experiência abortiva.

Devido ao conteúdo intimista da pesquisa, foi necessária uma aproximação cuidadosa às mulheres. Para tanto, a pesquisadora atuou como profissional em serviço, já que era residente do Curso de Especialização em Saúde da Mulher do Hesfa/UFRJ, que se estrutura na modalidade de Residência Multiprofissional, caracterizada por ensino em serviço. Pôde, assim, participar das consultas ginecológicas, baseando-se na ação de saúde denominada consulta conjunta (modalidade de Interconsulta) e objetivando criar uma relação de confiança com as participantes da pesquisa e contribuir no cuidado a elas destinado.

Após participar da consulta ginecológica e estando a paciente dentro dos critérios de inclusão na pesquisa, o convite para a participação na mesma era realizado de acordo com a Resolução no 466/2012, que trata de pesquisa com seres humanos do Conselho Nacional de Saúde do Ministério da Saúde. Este estudo teve parecer "aprovado" para sua realização em junho de 2015, com o número 1.102.403, pelo Comitê de Ética em Pesquisa da Escola de Enfermagem Anna Nery e do Instituto de Atenção à Saúde São Francisco de Assis da Universidade Federal do Rio de Janeiro (CEPE/EEAN/Hesfa/UFRJ).

Foram realizadas 15 entrevistas de acordo com os critérios de inclusão estabelecidos nesta pesquisa: mulheres com idade igual ou superior a 18 anos; usuárias do ambulatório de enfermagem 
ginecológica da UCB; que vivenciaram a experiência de um aborto provocado e que tal informação constasse no prontuário da usuária. As entrevistas foram realizadas logo após a consulta ginecológica em consultórios da UCB e eram iniciadas com a seguinte questão: "para você o que é ter autonomia sobre o seu corpo?" (após a apresentação da pesquisadora, explicação da pesquisa e assinatura do Termo de Consentimento Livre e Esclarecido).

A técnica de análise de dados elencada foi a análise de discurso francesa. Tal técnica tem como pressuposto a ideia de que a linguagem tem uma importância central na construção da vida social, não sendo ela um meio neutro de refletir ou descrever o mundo. Gill (2008) pensa a análise de discurso como tendo quatro temas principais: preocupação com o discurso em si mesmo; visão da linguagem como construtiva (criadora) e construída; ênfase no discurso como uma forma de ação; e convicção na organização retórica do discurso.

No que diz respeito à prática da análise, primeiramente foi realizada a transcrição detalhada das entrevistas, "a transcrição não pode sintetizar a fala, nem deve ser 'limpada', ou corrigida; ela deve registrar a fala literalmente, com todas as características possíveis da fala" (Gill, 2008, p. 251). Uma vez feita a transcrição, iniciou-se a leitura cética do material, ou seja, uma suspensão da crença daquilo que é tido como dado e em seguida codificou-se o material estudado. Tendo sido completada a codificação, pôde-se começar a análise, captando a marca linguística e relacionando-a ao contexto sócio-histórico.

\section{Resultados}

A maior parte das participantes eram oriundas da Região Sudeste (oito), mas chamou atenção o fato de sete delas serem das Regiões Norte e Nordeste do país. Mais da metade completou o ensino fundamental (11), apenas quatro tinham o ensino fundamental incompleto. Sobre a faixa etária, o público entrevistado concentrou-se entre 18 e 67 anos. No que tange à religião, o quantitativo manteve-se maior nas religiões mais populares do país, a católica (cinco) e evangélica (seis), porém, ao serem perguntadas se praticavam a religião declarada, dez informaram que sim, enquanto cinco relataram que não praticavam. Em relação à cor de pele declarada, os valores mais significativos foram para as cores parda (oito), negra (três) e branca (três).
Sobre sua vida familiar, seis participantes declararam ter um companheiro, enquanto que nove delas relataram não ter um relacionamento fixo. Atualmente, 13 delas estão em um trabalho remunerado e a média da renda familiar por mulher foi de $\mathrm{R} \$ 1.728,31$.

Ao falarem sobre seu histórico reprodutivo, 13 delas se declararam mães, sendo cinco a maior quantidade de filhos declarada por uma participante. A média de filhos das entrevistadas foi de 2,5 filhos por mulher. A média de gestações por mulher foi de 4,3, enquanto a média de abortos foi de 1,7 por mulher. A maior quantidade de gestações em uma participante foi de oito gravidezes e de abortos, quatro interrupções. No que concerne ao total de abortos, foram 26 experiências abortivas.

A partir da análise de dados elencada, empregou-se a codificação do material transcrito, que consiste em relacionar os discursos das participantes com as formações ideológicas que os regem, resultando nas categorias apresentadas a seguir, relacionadas de acordo com os objetivos deste trabalho.

\section{Entendimento das participantes acerca da autonomia sobre o seu corpo}

Neste item, as categorias resultantes foram: "Fazer o que quiser com o corpo"; "Cuidar do corpo"; "Respeitar o corpo"; "Preservar o corpo" e "Práticas ligadas à estética corporal". Nas falas das participantes "Fazer o que quiser com o corpo" relacionou-se à possibilidade de fazer suas próprias escolhas, inclusive no que diz respeito a seu parceiro; decisões acerca de sua gestação e práticas sexuais; de poder responder sobre seu corpo sem precisar justificar-se; e de não se prender a compromissos e relacionamentos que não deseje.

Acho que ter liberdade é ter liberdade de tudo. De você fazer o que quiser, sair pra onde você quer. Eu acho na minha cabeça isso. Não ter compromisso com ninguém. Acho na minha cabeça que liberdade é isso (Acácia, 59 anos).

A gente decidindo se você quer aquela gestação ou não. Porque não adianta. Tá, tudo bem, em termos de religião é algo que ninguém gosta. Mas você tem que pesar os prós e contras. E, pesando os prós e contras, apesar de ser totalmente contra essa prática [aborto], eu me vi sem alternativa. Me arrependo?! Me arrependo. Mas as minhas 
contas eu vou acertar com Deus. No momento era melhor pra mim (Azaleia, 54 anos).

Nos relatos, "Cuidar do corpo" surgiu com o sentido de conhecer o próprio corpo, o que é melhor para ele e preocupar-se com a saúde física.

Ah, tem gente que não valoriza o seu corpo, que não se cuida. Mulheres que não vão ao ginecologista fazer preventivo e têm outras que já tem essa preocupação, que cuidam melhor do seu corpo. [...] é ela [a mulher] quem vai saber o que é melhor pro corpo dela. Igual, têm mulheres que, fisicamente falando, gostam de ir pra academia, outras que não (Cravina, 24 anos).

A categoria "Respeitar o corpo" no discurso das entrevistadas apareceu vinculada a respeitar os limites físicos e morais e não prejudicar a própria saúde. A categoria "Preservar o corpo" se aproxima da anterior, porém, nas falas das entrevistadas, esteve mais relacionada à sexualidade, no sentido de poder ser prejudicial ter diversos parceiros sexuais culminando até em uma perda precoce da juventude.

Olha, a liberdade que elas têm sobre o corpo delas é fazer o que elas querem, entendeu?! Pela liberdade sobre o meu corpo, sobre a minha pessoa é fazer o que eu quero. Mas não é porque eu tenho a liberdade de fazer o que eu quero que eu vou fazer o que der na minha telha ou o que eu acho que tá certo, entendeu?! Porque... hoje eu tenho meu corpo assim, eu tô inteira, eu tô enxuta, eu tô isso e aquilo outro, e mais tarde? Né?! Porque quanto mais tarde fica, mais você vai perdendo fibra, você vai perdendo elasticidade, você vai perdendo, entendeu? Você não é mais aquela pele bonita, não tem mais aquele corpo lindo que você tinha, porque você abusou dele né?! Você usou da sua liberdade pra abusar do seu próprio corpo, entendeu?! Eu penso assim! O meu ponto de vista é esse, sobre a minha liberdade de ser! (Margarida, 40 anos).

Já a "Prática ligada à estética corporal” mostrou-se relacionada à liberdade de fazer mudanças no corpo, como por exemplo, realizar cirurgias plásticas, mudar a cor do cabelo, fazer tatuagem, praticar exercícios físicos, escolher que roupa usar. Além disso, também se relacionou ao receio de perder a beleza e a juventude.
A não ser que faça uma plástica, tire um pouco da gordura. Depois que a gente fica assim [a participante aponta para a própria barriga]! Na verdade, eu queria voltar ao que eu era antes. Queria nunca ter casado, queria nunca ter filho, eu queria ter o meu corpo todo tempo bonitinho, saradinho. E não é, entendeu?! E depois que a gente casa a gente se transforma, não é mais a mesma coisa (Camélia, 46 anos).

\section{Articulação do entendimento acerca da autonomia sobre o corpo com a experiência de aborto}

Questionamos às participantes se percebiam alguma relação entre a escolha de praticar um aborto e o entendimento exposto por elas a respeito da autonomia sobre o corpo. Das 15 participantes, 11 posicionaram-se positivamente, ou seja, percebiam a existência de tal relação.

Tem. Porque o aborto, eu analiso ele dessa forma, é uma coisa agressiva da mulher. Mas, às vezes, é uma coisa necessária, infelizmente. Porque em alguns casos... Eu não sou a favor do aborto! Acho que a pessoa tem que se prevenir pra não acontecer, mas em alguns casos não tem como. Às vezes, a pessoa é jovem não tem experiência nenhuma. Às vezes, também, é violentada. Então nesse ponto eu defendo sim, infelizmente. Porque é uma vida, é uma criança, mas em alguns casos eu defendo (Rosa, 62 anos).

Tem. Porque quando você pratica um aborto não é normal, porque a criança não pediu pra nascer. Aí você vai pensar: "eu trabalho em casa de família, eu estudo eu moro, eu dependo de casa de família". Meus pais não têm como me ajudar e eu vou chegar em casa com mais um filho?! Aí, a gente pede perdão a Deus. Aí vai ficar defeituosa, com o peito caído, se eu pensasse antes o que eu penso agora eu não teria é nenhum! Teria me cuidado mais. E muitas mulheres, te garanto que pensam assim. Te garanto que se elas poderem abortar, elas abortam pra não ficarem defeituosas! Mas que não é o normal, não é o normal (Camélia, 46 anos).

Tal posicionamento foi confirmado pelas respostas das entrevistadas, que indicaram o aborto como 
uma alternativa: quando a mulher não está preparada para ser mãe; quando a mulher não quer se prender a um relacionamento que não deseja; quando não quer perder sua beleza. Assim, relataram que o aborto é permeado por diversas influências (pouca experiência, não se sentir pronta, falta de apoio financeiro e familiar etc.) e, mesmo havendo outras pessoas envolvidas, o peso maior da escolha caberia a mulher. Desse modo, entendem que as mulheres deveriam poder sustentar suas decisões apesar das opiniões de terceiros, tendo o direito de decidir. Apesar disso, veem como irresponsabilidade a mulher que aborta conhecendo os métodos contraceptivos.

Eu tava tomando remédio, aí eu esquecia. Aí acabava vindo e eu pensava comigo "não, não é o momento agora... não quero ter filho". Falava isso quando eu tinha 17 anos. Aí eu fiquei grávida, foi meu primeiro aborto. Meu namorado não queria e eu gostava tanto dele, e eu também fiquei com medo de contar pra minha mãe. Minha mãe já sabia que eu não era mais virgem, ela já sabia que eu tinha relação e tal. Minha mãe ia aceitar, na boa [a gravidez]. [...] Mas eu fiquei com vergonha. Tipo assim, eu fiquei pensando "vai que não dá certo, eu vou ter que ficar sozinha com essa criança. Como é que eu vou trabalhar, vou deixar com a minha mãe?!". E eu nunca quis isso, ter um filho e deixar com a minha mãe pra eu poder trabalhar... entendeu?! (Violeta, 44 anos).

As respostas das quatro participantes que não acreditam que o aborto esteja relacionado ao seu entendimento de autonomia sobre o corpo estavam ligadas a um entendimento de que as mulheres que abortam estão desperdiçando a oportunidade de serem mães, de que o aborto prejudica a saúde da mulher e de que muitas abortam apenas em prol da manutenção da beleza física.

Porque eu não vejo sob esse ponto de vista! Pode ser que têm muitas mulheres que de repente engravida sem querer, digamos que é uma gravidez indesejada. A partir da hora que ela engravida sem ter desejado, o que vem geralmente na cabeça das mulheres: "que ela não quer". Muitas usam isso, o aborto, porque não querem ter uma deformação no corpo. Sabem que se continuar com aquela gravidez vai engordar, vai deformar o corpo dela, vai ficar feia, horrorosa. Muita gente pensa isso. Eu já fui ao contrário, quando eu tava grávida, eu tava mais linda, mais viva, era isso que os outros falavam (Margarida, 40 anos).

Por fim, foi perguntado às participantes como percebiam seu poder de decisão diante das gestações que resultaram em aborto. As falas sinalizaram um entendimento de que, apesar de o aborto ter sido um ato que trouxe arrependimento, foi uma decisão da mulher, tendo um peso significativo o fato de sentirem-se prontas ou não para terem um filho. Também surgiu o entendimento da impossibilidade de decidir sobre sua gestação quando o aborto é resultado de uma imposição.

Porque foi algo que não planejei, pedi pra que não acontecesse e a pessoa insistiu e aconteceu. E eu não me sentia com nenhuma estrutura. Embora ele me deu todas as possibilidades de assumir e tudo, mas eu me sentia forçada a aceitar uma situação de casamento. Eu falei: "Não, não é isso que quero pra minha vida. Não nesse momento" (Azaleia, 54 anos).

Não tinha, porque eu era de menor. Eu tava ainda pelos meus pais. Ele não era meu pai, era meu padrasto, mas foi quem me criou. Mas eu tava no poder deles e fui obrigada. Eu trabalhava, mas eu não sabia [que estava grávida] quando eu vim saber eu estava com sete meses. A mulher já tinha colocado o negócio lá dentro. Aí ali eu fiquei arrasada, porque foi um pedaço meu que saiu. Eu não cuidei de mim e tive que fazer isso por causa da minha mãe e do meu pai (Acácia, 59 anos).

Duas participantes relataram que, tendo sido o aborto uma consequência da dificuldade financeira e falta de apoio, esse não teria sido um ato de liberdade de escolha. Assim, entendem que mulheres com melhores condições (situação familiar e financeira estáveis, acesso a informação etc.) teriam mais liberdade de decisão diante de uma gravidez indesejada.

Aí como é que ia ficar?! Mais um, né?! Eu tirei um filho eu tava de um mês de um. Não minto! É, eu tava com meu pequenininho sem lugar pra morar, sem ter onde ficar, sem trabalho, enfim, sem nada e mais uma boca comigo e engravidei. [...] Aí imagina! Aí não é tanto ter a liberdade de tirar o meu 
filho, não é. É a necessidade! Muitas que têm a cabeça no lugar, que não anda fazendo besteira, que sabe o que anda fazendo da vida, mas têm muitas que é avoada faz assim... (Margarida, 40 anos).

\section{Discussão}

Em consonância com o aporte teórico adotado para a análise dos dados, torna-se relevante destacar o cenário em que tal pesquisa foi desenvolvida. O espaço ambulatorial mostrou-se um local frutífero para a obtenção de relatos das mulheres ali atendidas. Diniz e Medeiros (2010) destacam que os principais estudos sobre o aborto no Brasil utilizam três tipos de abordagens metodológicas: registros de internações hospitalares relacionadas ao aborto; abordagens na beira do leito às mulheres internadas por complicações no aborto; e, no terceiro tipo, há uma combinação de novas técnicas de coleta de dados e procura-se pesquisar o fenômeno aborto fora do ambiente hospitalar.

Esta pesquisa buscou escutar mulheres dentro do ambiente hospitalar, porém fora de um ambiente de internação que, por vezes, pode ser intimidador. Suas falas se deram em um momento de suas vidas no qual o episódio abortivo não era recente, podendo, assim, ter um impacto menos vívido do que no momento em que o mesmo se deu.

A estratégia de aproximação das participantes foi favorecedora, pois elas demonstraram segurança ao falar sobre o assunto proposto. $\mathrm{O}$ cenário de pesquisa escolhido, um ambulatório para consultas ginecológicas, foi um ambiente que propiciou uma sensação de confiança às entrevistadas, para que falassem sobre experiências relacionadas à vivência corporal. Também foi possível perceber como as temáticas abordadas nesta pesquisa aparecem de forma rotineira no dia a dia dos profissionais ali presentes, mostrando a importância de os profissionais de saúde estarem aptos para a abordagem de tais questões.

Soares, Galli e Viana (2010) apontam que o abortamento é parte significativa da demanda de mulheres que procuram os serviços de saúde, sendo esse um momento de vulnerabilidade física e emocional das usuárias. Citam, ainda, que há uma violação do direito ao atendimento e à informação e da autonomia em relação à decisão de interrupção da gravidez. Relatam também que com frequência o atendimento a essas mulheres nos hospitais é desumano, marcado por longas esperas, jejum, ausência de informação, violação da privacidade, atitudes de recriminação, culpabilização e punição das usuárias.

Além disso, muitas atitudes dos profissionais de saúde são marcadas por valores morais e religiosos, influenciando de forma negativa o atendimento prestado às usuárias. Nesse sentido, o Ministério da Saúde criou a Norma Técnica de Atenção Humanizada ao Abortamento, a fim de orientar os profissionais de saúde sobre os cuidados dispensados a essas mulheres com o intuito de conscientizar sobre a discriminação e a desumanização no atendimento, considerando a atenção integral à saúde (Brasil, 2011a).

Muitos profissionais de saúde são católicos ou evangélicos e têm problemas para realizar o aborto, por transferirem suas crenças religiosas para a atuação profissional. Muitos explicam suas resistências em função de um posicionamento de defesa da vida. Todavia, com posturas opostas à preservação da vida das mulheres, o profissional de saúde julga a mulher, adota atitudes punitivas e discriminatórias, boicota o atendimento ou se recusa a realizar o procedimento de aborto legal (Soares et al., 2010, p. 41).

A postura dos profissionais no local de realização desta pesquisa foi a de acolher a fala das mulheres ali atendidas com o intuito de orientá-las. Tal forma de trabalho auxiliou na abordagem às participantes e na obtenção de relatos fidedignos diante de um assunto de difícil abordagem como o aborto.

Oespaço de consultaginecológica que, em primeiro momento, pode parecer um ambiente de difícil atuação para o profissional da Psicologia, por meio da técnica da Interconsulta, revelou ser um espaço importante para uma atuação multiprofissional, no qual a compreensão sobre a subjetividade das usuárias somou-se aos procedimentos da Enfermagem. No mais, ressaltamos o posicionamento do Conselho Federal de Psicologia sobre a necessidade de avanços no campo das políticas públicas de saúde sexual e reprodutiva e de seu repúdio a tentativas de implementação de retrocessos nesse campo, como no caso do Projeto de Lei no 5.069/2013 (Conselho Federal de Psicologia, 2015).

A percepção de autonomia sobre o corpo, relatada pelas participantes, apareceu articulada à liberdade de fazer escolhas e de, ao mesmo tempo, não precisar justificar tais escolhas. Porém, essa liberdade não seria irrestrita, havendo a necessidade de respeitar determi- 
nados limites. Isso pôde ser observado, por exemplo, quando nas respostas houve abertura para a possibilidade de a mulher ter diversos parceiros sexuais, mas também existiu o receio de tal prática representar um risco com a possibilidade de adquirir alguma Doença Sexualmente Transmissível ou de perder a juventude por ter relações sexuais com diferentes parceiros.

Quando as entrevistadas falaram sobre o aborto, tal ambivalência também esteve presente. Mesmo relacionando a decisão de praticar um aborto com a liberdade de fazer escolhas, essa opção precisou ser velada. Assim, tal liberdade é marcada por diversos influenciadores: arrependimento; culpabilização da mulher quando essa conhece os métodos contraceptivos; relação direta a efeitos negativos à saúde física do corpo; condições financeiras e familiares adversas; receio de perder a beleza e a juventude; (des)preparo para a maternidade etc.

Desta maneira, entendendo as falas das participantes sob a luz da teoria de Beauchamp e Childress (2011), observamos que a autonomia de praticar um aborto é influenciada tanto pelas intenções das mulheres quanto pelo contexto em que estão inseridas, no qual, ao mesmo tempo em que há uma fala progressista com relação à prática do aborto, essa fala está inserida em um contexto social de coerção. Assim, apesar dos avanços conquistados com relação à construção de um corpo social menos subjugado, parece que as mulheres ainda não têm força para expor e sustentar tal discurso. Falar sobre o aborto como uma liberdade de escolha em ambiente protegido é algo que se mostrou possível, no entanto, assumir tal posicionamento frente a um contexto de criminalização do aborto ainda é algo que faz a mulher se calar.

Também foi possível perceber como o imaginário feminino das participantes ainda é fortemente ancorado em expectativas sociais ligadas à maternidade que despertam valores associados a uma feminilidade tida como a guardiã da família e do cuidado com o outro. Badinter (2010) aponta para uma crescente tendência que vem ocorrendo nos últimos anos de recuperação da naturalização entre maternidade e feminilidade. A autora propõe que as crises econômicas recentes e a flexibilização dos papéis masculino e feminino são importantes ingredientes para esse novo movimento de redução do feminino à maternidade. Desse modo, reforça-se o ideário de boa mãe, e as mulheres acabam por assumir a maior parte das tarefas domésticas e o cuidado com os filhos, levando ao que chamamos hoje de "dupla jornada".
Desse modo, a mulher contemporânea encontra-se dividida (e culpada) entre as possibilidades de independência, alcançadas muito por conta do controle da sua capacidade reprodutiva (fruto das lutas femininas da década de 1970), e os deveres para com a família.

Com a temática do aborto não é diferente, mesmo as participantes afirmando a importância de poderem escolher, ainda existe um sentimento de culpa por não refletirem o ideal feminino de boa mãe. Desse modo, o aborto aparece carregado de um valor negativo, pois é entendido como um ato que vai de encontro a tal ideal e não como uma possibilidade de escolha legítima.

Scavone (2001) ressalta que a decisão de ser ou não ser mãe passou a ter uma dimensão reflexiva e racional a partir do advento das condições subjetivas, econômicas e sociais das mulheres. E, apesar do controle da fecundidade (principalmente através de drogas abortivas) não ser algo recente na história, a autora aponta que o advento da modernidade e da tecnologia contraceptiva e da concepção abriu espaço tanto para uma maior escolha da mulher quanto para o dilema de ser ou não mãe.

Tal dilema traduz como a questão de ter filhos perpassa a vida das mulheres de forma diferente do que da dos homens, pois, para muitas, acaba se traduzindo entre duas escolhas que dificilmente se integram: ou correspondem à expectativa de boa mãe e esposa ou se aventuram em caminhos opostos a esse. Scavone (2001) aponta ainda que, em estudos que analisam a questão da maternidade sob o ponto de vista das relações de gênero, quando se trata da relação que os adultos estabelecem com suas crianças, as mulheres ainda possuem uma relação mais comprometida com os filhos do que os homens.

$\mathrm{Na}$ fala das participantes, a falta de apoio familiar, e consequentemente do parceiro, foi um fator importante para a decisão pelo abortamento. Também houve o relato de como tal decisão recai de forma mais dura sobre a mulher. Tais dados retratam como as decisões com relação aos filhos recaem de forma mais intensa sobre as mulheres e como isso retrata as relações de gênero envolvidas na maternidade.

Ao falar sobre religião, a maior parte das participantes (10) informa ser religiosa, porém um número significativo de participantes (cinco) declarou não ser praticante. A religiosidade das entrevistadas esteve presente nas falas, no sentido de que um dia elas pediriam perdão a Deus por terem cometido o aborto. Porém, o fato de serem católicas ou evangélicas não foi um impeditivo 
para praticarem o aborto. O que nos faz pensar que talvez a religião esteja envolvida no debate sobre o aborto devido mais aos dogmas das igrejas do que necessariamente pela religiosidade das pessoas envolvidas.

A amostragem da pesquisa também corrobora com os dados que apontam o aborto como uma questão de saúde pública e de justiça social. Em pesquisa realizada pelo Ipas Brasil (organização não governamental de proteção à saúde sexual e reprodutiva das mulheres com foco no aborto) e pelo Instituto de Medicina Social da UERJ, com o apoio da área técnica de Saúde da Mulher do Ministério da Saúde, em 2007, constatou-se que no Brasil para três nascidos vivos há um aborto induzido; existe também uma disparidade regional na incidência do aborto induzido, pois as Regiões Norte e Nordeste registram as taxas mais altas, 40 abortamentos/ 1.000 mulheres; as adolescentes entre 15 e 19 anos que residem nas regiões Norte e Nordeste apresentaram os maiores riscos de aborto induzido, juntamente com o Distrito Federal, Mato Grosso do Sul e Rio de Janeiro; e as mulheres pretas e pardas estão expostas a uma proporção maior de óbitos (Adesse, \& Monteiro, 2007).

As mulheres entrevistadas para esta pesquisa são um retrato de tais dados: em sua maioria declararam-se pardas, são oriundas principalmente da Região Nordeste, suas experiências abortivas ocorreram, principalmente, na adolescência e a incidência de aborto neste trabalho foi alta, 26 no total para 15 entrevistadas, com média de 1,7 abortos por mulher.

Um dos comentários finais da pesquisa do Ipas referente à criminalização do aborto aponta que ele tem contribuído para aumentar a prática do aborto inseguro, impactando de forma grave na saúde e vida das mulheres (Adesse \& Monteiro, 2007). Estudos comprovam que, em países onde o aborto é legal, as taxas de sua prática tiveram queda: na Europa Ocidental o número de abortos inseguros é próximo de zero enquanto que na América do Sul há uma estimativa de três milhões (Cook et al., 2004; Guillaume, \& Lerner, 2007; Langer, 2002). O debate sobre o aborto precisa ser retirado da esfera penal e ser visto como uma questão de direito humano, sexual e reprodutivo das mulheres. Sua prática, além de um problema de saúde pública, envolve questões de desigualdade social, econômica, étnica e de gênero.

\section{Considerações finais}

Cada momento histórico direciona de forma diferente o entendimento sobre o que é ser mulher e quais são suas necessidades de saúde. Tais percepções não são estáticas, mas fazem parte da dinâmica de processos políticos, sociais e ideológicos pelos quais a sociedade passa e se transforma. Compreender como a saúde da mulher foi tratada no país nos últimos 30 anos nos ajuda a desenhar o caminho percorrido para se chegar à atual Política Nacional de Atenção Integral à Saúde da Mulher, criada em 2004, que defende uma saúde que aborda os diferentes aspectos da vida da mulher (Brasil, 2011b).

Tais avanços repercutiram no conceito de saúde reprodutiva, que foi amplamente discutido durante a Conferência das Nações Unidas sobre População e Desenvolvimento (CIPD) realizada no Cairo em 1994. Tal conferência foi um marco na luta pelo direito das mulheres, sendo o maior evento de porte internacional sobre temas populacionais realizados até então. A partir da CIPD, o controle populacional como condição para a melhoria da situação econômica dos países deixou de ser o foco, voltando-se para o pleno exercício dos direitos humanos e dos direitos da mulher como fatores determinantes para a qualidade de vida dos indivíduos, reconhecendo que o direito reprodutivo é um direito humano e um elemento fundamental da igualdade de gênero.

Para a OMS, saúde é o estado pleno de bem-estar físico, mental e social, e não apenas a ausência de doença ou enfermidade. Por isso, ao pensar na saúde sexual e reprodutiva, precisamos percebê-la em um quadro mais amplo, indo além do tratamento e orientações sobre a reprodução e as doenças sexualmente transmissíveis e incluindo a melhoria da qualidade de vida das pessoas e de suas relações pessoais.

Assim, a partir desse entendimento, este estudo teve o intuito de abordar como o aborto toca o imaginário feminino e até que ponto o que a mulher entende sobre si e seu corpo reflete em uma possível prática de aborto, pois são as mulheres que vivenciam tal situação que precisam ser cada vez mais ouvidas e suas experiências, cada vez mais valorizadas. Para que possamos promover uma assistência de qualidade e um atendimento mais humanizado em prol de uma escuta qualificada sobre os motivos de as mulheres desejarem engravidar ou abortar e as dificuldades que tenham para a prevenção da gravidez, é necessário possibilitar, também, que as mulheres sejam cada vez mais ouvidas nos debates acerca do aborto e da autonomia reprodutiva, visto que elas são as que mais vivenciam as repercussões dessas discussões. 
Nesse sentido, o referencial teórico utilizado se mostrou adequado para a reflexão sobre a autonomia como um conceito polissêmico, atravessado por diversos influenciadores que provoca ambivalência e toca cada um de uma forma singular. Por isso, tal con- ceito precisa ser publicizado e debatido de forma que se aproxime cada vez mais do dia a dia das pessoas, para que, assim, possamos discutir de forma coletiva os significados da autonomia reprodutiva no universo da mulher brasileira.

\section{Referências}

Adesse, L., \& Monteiro, M. F. G. (2007). Magnitude do aborto no Brasil. IPAS Brasil. Recuperado de http://www.ipas.org.br/arquivos.

Aquino, E., \& Menezes, G. (2009). Pesquisa sobre o aborto no Brasil: avanços e desafios para o campo da saúde coletiva. Cadernos de Saúde Pública, 25(Supl. 2), 193-204. https://doi.org/10.1590/S0102-311X2009001400002

Badinter, E. (2010). Le conflit, la femme et la mère. Paris: Flammarion.

Barroco, M. L. S. (2009). Ética: fundamentos sócio-históricos (2a ed.). São Paulo, SP: Cortez.

Beauchamp, T. L., \& Childress, J. F. (2011). O respeito à autonomia. In T. L. Beauchamp, \& J. F. Childress, Princípios de ética biomédica (pp. 137-207). São Paulo, SP: Loyola.

Brasil. (1998). Câmara dos Deputados. Projeto de Lei $n^{\circ} 4.703$. Acrescenta o inciso VIII e o $\$ 1^{\circ}$ ao art. $1^{\circ}$ da Lei ${ }^{\circ}$ 8.072, de 25 de julho de 1990. Recuperado de: http://www.camara.gov.br/proposicoesWeb/fichadetramitacao?idProposicao $=21071$

Brasil. (2013). Câmara dos Deputados. Projeto de Lei no 5.069, de 27 de fevereiro de 2013. Acrescenta o art. 127-A ao Decreto-Lei no 2848, de 7 de dezembro de 1940. Recuperado de: http://www.camara.gov.br/proposicoesWeb/ fichadetramitacao?idProposicao $=565882$

Brasil. (2012). Conselho Nacional de Saúde. Resolução No 466. [Aprova diretrizes e normas regulamentadoras de pesquisa envolvendo seres humanos]. Recuperado de http://conselho.saude.gov.br/resolucoes/2012/Reso466.pdf

Brasil. (1940). Decreto-Lei No 2.848, de 7 de dezembro de 1940. Código penal. Diário Oficial da União, 31 dez. 1940.

Brasil. (2009). Departamento de Ciência e Tecnologia, Secretaria de Ciência, Tecnologia e Insumos Estratégicos. 20 anos de pesquisas sobre aborto no Brasil. Brasília, DF: Ministério da Saúde.

Brasil. (2011a). Ministério da Saúde. Secretaria de Atenção à Saúde. Departamento de Ações Programáticas Estratégicas. Atenção humanizada ao abortamento: norma técnica (2a ed.). Brasília, DF: Ministério da Saúde.

Brasil. (2011b). Ministério da Saúde. Secretaria de Atenção à Saúde. Departamento de Ações Programáticas Estratégicas. Política nacional de atenção integral à saúde da mulher: princípios e diretrizes. Brasília, DF: Ministério da Saúde.

Brasil. (2008). Ministério da Saúde. Secretaria de Ciência, Tecnologia e Insumos Estratégicos. Departamento de Ciência e Tecnologia. Agenda nacional de prioridades de pesquisa em saúde. Brasília, DF: Ministério da Saúde.

Brasil. (2014, 09 de maio). Portal Brasil. Saúde. OMS: Brasil reduz mortalidade materna em 43\% de 1990 a 2013. Recuperado de http://www.brasil.gov.br/saude/2014/05/oms-brasil-reduz-mortalidade-materna-em-43-de-1990-a-2013

Colling, A. (2004). A construção histórica do feminino e do masculino. In S. T. L. Cabeda, M. N. Strey, \& D. R. Prehn (Orgs.), Gênero e cultura: questões contemporâneas (pp. 13-38). Porto Alegre, RS: EDIPUCRS.

Conselho Federal de Psicologia. (2015, 23 de setembro). Nota de repúdio do CFP ao PL que veda atendimento às vítimas de violência sexual no SUS. Recuparado de http://site.cfp.org.br/nota-de-repudio-do-cfp-ao-pl-50692013/

Cook, R. J., Dickens, B. M., \& Fathalla, M. F. (2004). Saúde reprodutiva e direito humanos: integrando medicina, ética e direito. Rio de Janeiro, RJ: CEPIA.

Diniz, D., \& Medeiros, M. (2010). Aborto no Brasil: uma pesquisa domiciliar com técnica de urna. Ciência \& Saúde Coletiva, 15(Supl. 1), 959-966. https://doi.org/10.1590/S1413-81232010000700002

Gill, R. (2008). Análise de discurso. In: M. W. Bauer, \& G. Gaskell. Pesquisa qualitativa com texto, imagem e som: um manual prático (pp. 244- 270). Petrópolis, RJ:Vozes.

Guillaume, A., \& Lerner, S. (2007). El aborto en América Latina y el Caribe: uma revisión de la literatura de los años 1990 a 2005. Paris: CEPED. 
Langer, A. (2002). El embarazo no deseado: impacto sobre la salud y la sociedad en América Latina y el Caribe. Revista Panamericana de Salud Publica, 11(3), 192-205. Recuperado de http://www.scielosp.org/pdf/rpsp/v11n3/9402.pdf

Machado, M. D. C. (2012). Aborto e ativismo religioso nas eleições de 2010. Revista Brasileira de Ciência Política, (7), 25-54. https://doi.org/10.1590/S0103-33522012000100003

Rossi, M. (2015, 31 de outubro). Mulheres vão às ruas: "Pílula fica, Cunha sai". El País. Recuperado de http://brasil.elpais.com/brasil/2015/10/30/politica/1446222175_318913.html

Scavone, L. (2001). Maternidade: transformações na família e nas relações de gênero. Interface (Botucatu), 5(8), 47-60. https://doi.org/10.1590/S1414-32832001000100004

Soares, G. S., Galli, M. B., \& Viana, A. P. A. L. (2010). Advocacy para o acesso ao aborto legal e seguro: semelhanças no impacto da ilegalidade na saúde das mulheres e nos serviços de saúde em Pernambuco, Bahia, Paraíba, Mato Grosso do Sul e Rio de Janeiro. Recife, PB: Grupo Curumim.

Swain, T. N. (2000). A invenção do corpo feminino ou “a hora e a vez do nomadismo identitário?”. Textos de História, $8(1-2), 47-84$.

\section{Camila Simões Santos}

Formada em Psicologia pela Universidade Federal do Rio de Janeiro - UFRJ em 2011. Atuação profissional na área de Psicologia Organizacional. Atualmente é Residente Multiprofissional em Saúde da Mulher pela UFRJ e está cursando especialização em Psicologia Clínica - Gestalt Terapia pelo IGT/CFP. Tem experiência como professora do curso preparatório Escola Preparatória.

E-mail: kmilasimoes@gmail.com

\section{Lia Marcia Cruz da Silveira}

Mestrado em Educação nas Ciências e Saúde pela Universidade Federal do Rio de Janeiro (UFRJ, 2003). A partir de 2010 atua como Técnica em Assuntos Educacionais e Co-coordenadora do Programa de Residência Multiprofissional em Saúde da Mulher do Instituto de Atenção à Saúde São Francisco de Assis - Hesfa/UFRJ. Desde 2012, atua como Coordenadora Pedagógica do Curso de Desenvolvimento de Competência Pedagógica para a Prática da Preceptoria - ABEM/SGTES/OPAS. Tem experiência na área de Psicologia, atuando principalmente nos seguintes temas: Formação Profissional, Residências Médica e Multiprofissional, Saúde Mental com ênfase em Distúrbios Psicossomáticos e Atenção Primária à Saúde.

Endereço para envio de correspondência: Universidade Federal do Rio de Janeiro, Hospital Escola São Francisco de Assis.

Av. Presidente Vargas, 2.863. Centro. 20210-030

Rio de Janeiro - RJ, Brasil.

Recebido 13/02/2016

Reformulação 28/11/2016

Aprovado 13/02/2017

Received 02/13/2016

Reformulated 11/28/2016

Approved 02/13/2016

Recebido 13/02/2016

Reformulado $28 / 11 / 2016$

Aceptado 13/02/2017 
Santos, C. S., \& Silveira, L. M. C. (2017). Percepção de Mulheres sobre o Aborto e Autonomia do Corpo.

Como citar:Santos, C. S., \& Silveira, L. M. C. (2017). Percepções de mulheres que vivenciaram o aborto sobre autonomiado corpo feminino.Psicologia:CiênciaeProfissão, 37(2),304-317.https://doi.org/10.1590/1982-370300352015

How to cite: Santos, C. S., \& Silveira, L. M. C. (2017). Perceptions related to the autonomy of the female body by womenwhohadabortions. Psicologia:CiênciaeProfissão, 37(2),304-317.https://doi.org/10.1590/1982-370300352015

Cómo citar:Santos, C. S., \& Silveira, L. M. C. (2017). Percepciones sobre autonomía del cuerpo remenino de mujeres queexperimentaronaborto.Psicologia:CiênciaeProfissão,37(2),304-317.https://doi.org/10.1590/1982-370300352015 